\title{
Analysis of contingencies through the sensitivity factors of the National Electricity Interconnected System. A case study in Ecuador
}

\author{
Andre Alvarado*, Jimmy Asqui ${ }^{\dagger}$, Juan Plazarte $^{\ddagger}$, and Javier Urquizo ${ }^{\S}$ \\ Escuela Superior Politécnica del Litoral, ESPOL, FIEC \\ Campus Gustavo Galindo Km 30.5 Vía Perimetral, Guayaquil, Ecuador \\ Email:*anjoalva@espol.edu.ec, ${ }^{\dagger}$ jasqui@espol.edu.ec, ${ }^{\S}$ jurquizo@espol.edu.ec \\ TRANSELECTRIC, Departamento de Planificación de la Expansión \\ Avenida 6 de Diciembre y Orellana, Quito, Ecuador \\ Email: juan.plazarte@celec.gob.ec
}

\begin{abstract}
This article is based on a simple contingency analysis using sensitivity factors in the IEEE fourteen bus system, and later in the National Interconnected System (SNI) in the Republic of Ecuador. The Ecuadorian network was analysed during the dry season, considering maximum demand, for the year 2018. A reduction in calculation time considered the use of the load flow in direct current. Through the Line Outage Distribution Factors (LODFs), the impact on the redistribution suffered by the transmission lines corresponds to the system when the outage of an element is known. On the other hand, with the matrix of Power Transfer Distribution Factors (PTDFs), the state of the transmission lines is known given a change in the transfer of power from one area to another. With this consideration in mind, energy transfers between the neighbouring countries of Colombia and Perú are evaluated. MatPower ${ }^{T M}$ was used as an aid to discern the ability of the system under certain conditions for the calculation in percentage of the loadings of the transmission lines, belonging to a fourteen bus system and then in the SNI. Once the simulations were carried out, there were overloads in the front of the contingency in the lines of the system, for which these affectations are considered by the operators of power systems to be able to mitigate their affectation in the network, by making use of the LODF factors. The results of the fourteen bus system with a power transfer of $70 \mathrm{MW}$, using the factors, showed that two lines were overloaded. On the other hand, the worst scenario in the SNI occurred with the export of $500 \mathrm{MW}$ of energy to Colombia. In this scenario, three lines had overloads $100 \%$ greater than their capacity. This sensitivity approach provides the potential for electricity planners and other bodies to increase their ability to take control actions for higher order contingencies.
\end{abstract}

\section{INTRODUCTION}

The National Interconnected System (SNI) [1] is a set of parts and elements, the main ones being generators, transformers, transmission lines, and loads, among others, with a plausible and desirable convergence of the trends, forces, and policies in play. In Ecuador, the Government Energy Minister (MEER) [2] has the objective of making electric power available from the electric generation units to the consumption centres through transmission lines that are interconnected. This allows electricity to be transported under the programming operation of the National Centre for Energy Control (CENACE) [3], [4].

The Electricity Corporation of Ecuador (CELEC EP) transports electric power to the country through the National Transmission System, and the operation and maintenance is carried out by its TRANSELECTRIC Business Unit. In the last decade, the electricity sector has focused on guaranteeing supply under sovereign conditions, through the development of local energy resources and prioritizing the participation of renewable energies [4] to promote the diversification of the energy matrix. The institutionalism of the Ecuadorian electric sector was also strengthened, and the administrative management of electric utilities has been improved. The national generation and transmission system is comprised of different elements that guarantee the correct operation from the point of generation to the loading points. It is important to simulate the present and future operation of the national system of Ecuador with estimated load and generation data of the country. The SNI is divided into electrical zones to facilitate the restoration of the network or future integration [5], [6]. The electrical system is composed of hydroelectric and thermal generation, in which, by including the $500 \mathrm{KV}$ transmission system, the ring is modified at the $230 \mathrm{KV}$ level, to supply areas of higher load due to the income of new electricity generation projects [4]. The system has $138 \mathrm{KV}$ branches, with sub-transmission systems at $69 \mathrm{kV}$ and distribution systems at $13.8 \mathrm{kV}$. In addition, there are two international interconnections, such as Colombia in the north and Perú in the south [7].

In electrical power systems, reliability and safety [8] are priority factors and the role of operators is to maximize these factors in the systems at all times. For this reason, a safety analysis of the power system is required when it is designed, and during normal operation and planning, so that the design can support failures in the network, for example when transmission lines are open and there are imperfections in the generating units [9]. Moreover, the reliability of the power system is equally important when it comes to the supply of electrical energy, and it is necessary to carry out different electrical studies, for which a contingency analysis [10] can 
be performed. This method is employed to learn the state of one or more elements in the system, following a fault. An example of this might be when a transmission line has a fault and leaves the system, or when there are failures in several CENACE computers, which may be a greater contingency. In this case, the operator will have to take the correct measures before a certain contingency to avoid a cascade disconnection [9]. With our analyses, we seek to help the operators and planners of the power system know which elements cause greater problems, such as damage to equipment, or where there are blackouts, and, based on this information, help then to take corrective actions to solve these problems as fast as possible. Two main factors were used in these analyses, to determine the impact of power generation and load on power flows. These factors are: power transfer distribution factor (PTDF) and line outage distribution factor (LODF) [11], [12]. With the PTDF, a relative change in the load flow in a particular line is calculated due to the change in introducing and extracting power in a pair of buses. On the other hand, with the LODF, the redistribution of the load in the system is calculated, when an interruption occurs [13]. In our methodology, the PTDF factor proceeds without the need to use much iterations, because the calculation is linear, the factors can be superimposed when transfers are required between any pair of bars that are not directly connected, which is applied in this work when completing the PTDF matrix from any node to another node, by changing the PTDFs that exist by the direct connection between bars, that is, the sum of the corresponding factors to take the narrowest path. Whereas the LODF factor is based on the power calculation given a loss of a line i.e. the interruption of this element, and further the re-distribution of the remaining lines of the network, which are called monitored lines.

This paper focuses on a hitherto unexplored research questions, for which at present there is no definitive answer, which in essence relate primarily to the issues in emerging countries: What is the interest in conducting a safety assessment in a power system? How does it help to carry out a contingency analysis in an electric power system? What is the concept of sensitivity factors? What are the factors that were used to perform the contingency analysis? What are the major affectations once the contingency analysis has been carried out through sensitivity factors in the IEEE system of fourteen bars and the whole national interconnected system? How can security be improved in the National Interconnected System?, and in this way the operator will be able to take both preventive and corrective actions in the shortest possible time. Events, which affect on normal operation are unpredictable, for example, with the failure of a transmission line, the other lines must be able to transmit the generation, and thus the power flow is redistributed and there are no violations of any kind in its limits.

\section{Methodology}

In this paper, a contingency study was carried out for the Ecuadorian electricity grid. The methodology used to calculate the sensitivity factors is presented in Fig. 1, which shows the procedure followed to determine the given PTDF and LODF matrices obtaining system data. In the operative part, Matlab was used for the calculation procedures.

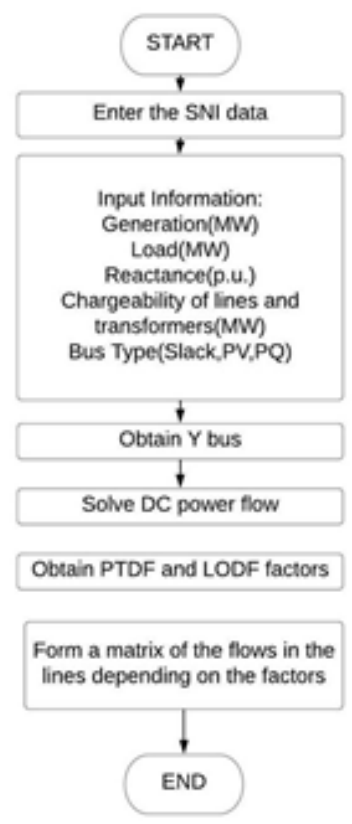

Fig. 1: Flow diagram of the methodology.

\subsection{Direct current model of load flow}

This paper contributes to the use of procedures and presents alternatives for understanding the behaviour of the system with the aim of taking actions both to prevent and correct possible problems in the network. Electric power systems are complex and there is a need for operators to know the current state. In this study, the DC power flow method was used to compute the active power due to its simplicity and robustness [14]. The considerations of this are: (1) the lines resistances $\mathrm{R} \ll$ $\mathrm{X}$ were not considered, (2) the differences in voltage angle are small, and, (3) the magnitudes of the voltages of the bus were established in 1.0 by unity. With these assumptions, voltage angles and active power injections were the problem variables.

For a power system with $\mathrm{N}$ buses, the active power injections are indicated in Equation 1.

$$
P_{i}=\sum_{j=1}^{N} B_{i j}\left(\theta_{i}-\theta_{j}\right)
$$

where, $B \_i j$ was the reciprocal of the reactance between the bus $i$ and the bus $j$.

As a result, the active power flow through the transmission line " $i$ ", between the " $s$ " and " $r$ " bus, was calculated [15] as shown in Equation 2.

$$
P_{L i}=\frac{1}{X_{L i}}\left(\theta_{s}-\theta_{r}\right)
$$

where $X \_L i$ was the reactance of line $L$. 
The DC load equations in matrix form are as detailed in Equation 3.

$$
\theta=[B]^{-1} P
$$

where $P$ is the vector $N \times 1$ of injections of net active power in the bus, $B$ is the matrix of susceptances of the system with $R$ $=0$, and $\theta$ is a vector $N \times 1$ of angles of tensions of the buses. $\mathrm{N}$ is the number of system buses. Then Equation 4 follows.

$$
P_{L}=(b \times x) \theta
$$

where $P_{L}$ is a vector of streams of lines (the number of lines), since it is a matrix (it is equal to the susceptance of the line and the non-diagonal elements are zero), $\mathrm{A}$ is a bus-line incidence matrix, and $\theta$ was a vector $N \times 1$ of voltage angles of the buses.

\subsection{The sensitivity factors}

In the operative part, the power flow is carried out with the MatPower ${ }^{\mathrm{TM}}$ tool, developed in MATLAB, in which the two most important factors were determined: the Power Transfer Distribution Factor (PTDF) and the Line Outage Distribution Factor (LODF) [15].

The power transfer distribution factor PTDF assumes a power transfer between a $p$ (send) bus and a $q$ (receive) bus, that is, there is a power injected in the $p$-bus and extracted from the $q$-bus. The PTDF gives the fraction of power that ends up flowing through a line $l$.

By definition, Equations (5) and (6)were obtained thus:

$$
\begin{gathered}
P T D F_{p q, l}=\frac{\Delta f_{l}}{\Delta P_{p q}} \\
\Delta f_{l}=f_{l}^{\sim}-f_{l}^{o}
\end{gathered}
$$

where $l$ is the index of the line, $p$ is the active power emitting node, $q$ is the active power receiving node, $f_{l}^{-}$is the flow on line $l$ when considering the power difference, $f_{l}^{o}$ is the flow in line $l$ of the original system, and $\Delta P_{p q}$ is the difference in power, generation and demand, compared to the initial configuration of the network [16].

With the above equation, Equation (7) is obtained as:

$$
f_{l}^{\sim}=f_{l}^{o}-P T D F_{p q, l} \Delta P_{p q}
$$

With which, the resulting new flow in the lines $l$ is calculated due to a power transfer from the bus $p$ to $q$, with the use of PTDF factors. If the transfer were in the opposite direction, from bus $q$ to bus $p$, we would have Equation (8):

$$
P T D F_{q p, l}=-P T D F_{p q, l}
$$

Finally, the range of these factors is established in Equation (9) [17].

$$
-1 \leq-P T D F_{p q, l} \leq+1
$$

LODF factors verify overloads when transmission lines are lost, by monitoring the effects on line $l$ when opening line $k$, which calculates the percentage of flow that appears in the other components. See Equation 10.

$$
L O D F_{l, k}=\frac{\Delta f_{l}}{f_{k}^{o}}
$$

where $\Delta f_{l}$ is the change in the power flow (in MW) in the line $l$ when a power transfer occurred between $p$ and $q, f_{k}^{o}$ is the original flow on the line $k$ before it is opened.

The output of the line is simulated by the injection of power in buses $p$ and $q$. If the line has been disconnected by means of switches, the power flows through the line is 0 .

Therefore, the PTDF factor is related to the LODF factor, as shown in Equation (11).

$$
L O D F_{l, k}=P T D F_{p q, l} \frac{1}{1-P T D F_{p q, k}} P_{p q}
$$

The LODF factor is calculated given the change in flow in line $l$ and the lost of the transmission line $k$ between buses $p$ and $q$. See Equation 12.

$$
f_{l}^{\sim}=f_{l}^{o}+L O D F_{l, k} P_{p q}
$$

The new resulting flow in lines $l$ and $k$ is calculated due to a power transfer from buses $p$ to $q$. [18]

\subsection{The input data}

The input data of the fourteen bus system are shown in Table I.

TABLE I: Generation data and charges in the fourteen bus system [19]

\begin{tabular}{|c|c|c|c|}
\hline Bus & Type & Generation (MW) & Load (MW) \\
\hline 1 & 1 & 219 & 0 \\
2 & 2 & 40 & 21.7 \\
3 & 2 & 0 & 94.2 \\
4 & 3 & 0 & 47.8 \\
5 & 3 & 0 & 7.6 \\
6 & 2 & 0 & 11.2 \\
7 & 3 & 0 & 0 \\
8 & 2 & 0 & 0 \\
9 & 3 & 0 & 29.5 \\
10 & 3 & 0 & 9 \\
11 & 3 & 0 & 3.5 \\
12 & 3 & 0 & 6.1 \\
13 & 3 & 0 & 13.5 \\
14 & 3 & 0 & 14.9 \\
TOTAL & - & 259 & 259 \\
\hline
\end{tabular}

Table 2 identifies the input values of the Ecuadorian network: generation, loading and type of bus. One refers to the reference bus, two to the $P V$ bus, and three to the $P Q$ bus, considering a scenario of maximum demand. For this analysis, the buses in Table II were considered input to the SNI. Table 2 shows the data corresponding to the bus of the SNI in maximum demand and in dryness 
TABLE II: Generation and load data in the SNI buses.

\begin{tabular}{|c|c|c|c|c|}
\hline Bus & Name & $\begin{array}{c}\text { Gen } \\
\text { (MW) }\end{array}$ & $\begin{array}{c}\text { Load } \\
\text { (MW) }\end{array}$ & Type \\
\hline 1 & B_Molino_138 & 405,2 & 0 & 1 \\
11 & B_Cuenca_138 & 0 & 0 & 3 \\
16 & B_Cuenca_69 & 0 & 7 & 3 \\
24 & B_Monay(3)_69 & 0 & 25,73 & 3 \\
33 & B_Turi(8)_69 & 0 & 26,27 & 3 \\
37 & B_Machala_230 & 0 & 0 & 3 \\
39 & B_Molino_230 & 384,52 & 0 & 2 \\
42 & B_Trinitaria_138 & 0 & 0 & 3 \\
46 & B_Pascuales_138 & 0 & 11 & 3 \\
49 & B_Chongon_138 & 0 & 0 & 3 \\
63 & B_Pascuales_230 & 0 & 0 & 3 \\
91 & B_Salitral_138 & 0 & 0 & 3 \\
199 & B_Jamondino_220 & 0 & 0 & 3 \\
200 & B_Frontera_Perú230 & 0 & 0 & 3 \\
\hline
\end{tabular}

Table 2 considers just a few of all the buses that form the Ecuadorian network. The other input values correspond to the reactance of the transmission lines of the fourteen bus system, and the SNI is obtained in Section 3.

\section{RESULTS}

In our results section, the fourteen bus system is presented first as a prototype, i.e. in section 3.1, the DC power flow is calculated, for the active power in each bus, angles, and the transmission lines power of the grid. This allows us to find errors at the start of our simulation, and to save time, and increase overall quality. Then in section 3.2 the results of the National Interconnected System, in which the results obtained are further interpreted.

\subsection{Results Analysis for the IEEE fourteen bus system}

In this section, we present the results obtained from the simulations so that the DC Flow information could be obtained in normal operation for this prototype system.

Once the simulations had been carried out, the values of active power flowing through the transmission lines of the network were obtained through the $D C$ flow. In the system database, the maximum capacity in $M W$ of these lines was obtained to have the respective loadings, and the reactances of the lines were taken into account in per unit.

The results of the DC flow run are shown in Table 3. From Table III it can be observed that there is a safe operating condition because no transmission line of the electric network surpasses $100 \%$ of the maximum capacity in $M W$.

Analysing the values of Table 3, in normal operation, there were no violations in the system lines, due to overloads. This is important to then compare the effect that the contingencies have for the system, which in our case were carried out by the distribution factors.
TABLE III: Power flows in DC for the power system in a no fault condition

\begin{tabular}{|c|l|c|c|c|}
\hline $\begin{array}{c}\text { Buses } \\
\text { From } \\
\text { - to }\end{array}$ & $\mathbf{X}$ (pu) & $\begin{array}{c}\text { Max } \\
\text { Flow } \\
\text { (MW) }\end{array}$ & $\begin{array}{c}\text { Limit } \\
\text { (MW) }\end{array}$ & $\begin{array}{c}\% \\
\text { Charge }\end{array}$ \\
\hline $1-2$ & 0.11834 & 73.94 & 100 & $73.94 \%$ \\
$1-2$ & 0.11834 & 73.94 & 100 & $73.94 \%$ \\
$1-5$ & 0.22304 & 71.12 & 100 & $71.12 \%$ \\
$2-3$ & 0.19797 & 70.05 & 100 & $70.05 \%$ \\
$2-4$ & 0.17632 & 55.23 & 100 & $55.23 \%$ \\
$2-5$ & 0.17388 & 40.90 & 100 & $40.90 \%$ \\
$3-4$ & 0.17103 & -24.15 & 100 & $24.15 \%$ \\
$4-5$ & 0.04211 & -62.34 & 100 & $62.34 \%$ \\
$4-7$ & 0.20912 & 28.99 & 100 & $28.99 \%$ \\
$4-9$ & 0.55618 & 16.63 & 100 & $16.63 \%$ \\
$5-6$ & 0.25202 & 42.08 & 100 & $42.08 \%$ \\
$6-11$ & 0.1989 & 6.30 & 100 & $6.30 \%$ \\
$6-12$ & 0.25581 & 7.55 & 100 & $7.55 \%$ \\
$6-13$ & 0.13027 & 17.03 & 100 & $17.03 \%$ \\
$7-8$ & 0.17615 & 0.00 & 100 & $0.00 \%$ \\
$7-9$ & 0.11001 & 28.99 & 100 & $28.99 \%$ \\
$9-10$ & 0.0845 & 6.20 & 100 & $6.20 \%$ \\
$9-14$ & 0.27038 & 9.92 & 100 & $9.92 \%$ \\
$10-11$ & 0.19207 & -2.80 & 100 & $2.80 \%$ \\
$12-13$ & 0.19988 & 1.45 & 100 & $1.45 \%$ \\
$13-14$ & 0.34802 & 4.98 & 100 & $4.98 \%$ \\
\hline
\end{tabular}

3.1.1 Results of the loadings of the lines before a contingency in the system of fourteen bus system through the LODF factors.

Table 4 shows the results corresponding to the loadings in $\%$ of all the lines before the outage of a transmission line, with the help of the LODF factors, taking into consideration equation (12).

The LODF factor is an effective reference for the overloads in the power system [15], because it is physically modified to the network due to the outage of transmission lines, and so monitoring when a power flow of $70 \mathrm{MW}$ is used as shown in Table IV. Here, the system is operating normally at maximum demand and the load limits are in a normal range.

TABLE IV: Chargeability results with LODF for different outputs in the lines of the fourteen-bus system

\begin{tabular}{|c|c|c|c|}
\hline Monitored Line & $\mathbf{1 - 2 a}$ & $\mathbf{1 - 2 b}$ & $\mathbf{1 - 5}$ \\
\hline $1-2 \mathrm{a}$ & $0 \%$ & $127.27 \%$ & $109.5 \%$ \\
$1-2 \mathrm{~b}$ & $127.27 \%$ & $0 \%$ & $109.5 \%$ \\
$1-5$ & $91.73 \%$ & $91.73 \%$ & $0.00 \%$ \\
\hline
\end{tabular}

As the first contingency event in abnormal operation, the opening of line 1-2a causes an alteration of chargeability in the other lines of the network, placing line $1-2 b$ in overload. When line $1-2 b$ is opened, this causes the same effect in the $1-2 a$, both with a value of $127.27 \%$.

In the second contingency event, the opening of line 1-5 causes two violations of the chargeability limit in the lines 
that are in parallel $1-2 \mathrm{a}, 1-2 \mathrm{~b}$ and both lines have overloads of $109.50 \%$.

In summary, the calculation of the sensitivity factors in a test system was carried out, in order to perform a contingency analysis to know the safety of the network. The state of the electrical network was previously known, and thus by means of an evaluation of the loadings of the elements of transmission, we can provide information about the post-contingency status. Depending on the outcome, we can make decisions for the improvement of the continuity of the electrical system.

3.1.2 Results of the loadings of the lines before a contingency in the system of fourteen bus system through the PTDF factors.

In Table $\mathrm{V}$, we have the percentage values of the overloads in the lines, taking into consideration Equation (7), with a power transfer of $70 \mathrm{MW}$, which was chosen to reveal the existence of overloads in the monitored lines when there is power transfer between two buses in the system. If the value of the transfer is low, for example less than $70 \mathrm{MW}$, the lines do not saturate, and continue working in normal operation.

TABLE V: Results of the affectation percentages of the PTDF factor in the lines for different power transactions between two buses in the fourteen bus system

\begin{tabular}{|c|c|c|c|c|}
\hline $\begin{array}{c}\text { Monitored } \\
\text { Line }\end{array}$ & $\mathbf{1 - 2 a}$ & $\mathbf{1 - 2 b}$ & $\mathbf{1 - 5}$ & $\mathbf{2 - 3}$ \\
\hline $1-2 \mathrm{a}$ & $103.27 \%$ & $103.27 \%$ & $95.31 \%$ & $70.74 \%$ \\
\hline $1-2 \mathrm{~b}$ & $103.27 \%$ & $103.27 \%$ & $95.31 \%$ & $70.74 \%$ \\
\hline $1-5$ & $82.46 \%$ & $82.46 \%$ & $98.38 \%$ & $77.52 \%$ \\
\hline $2-3$ & $68.14 \%$ & $68.14 \%$ & $77.52 \%$ & $109.21 \%$ \\
\hline
\end{tabular}

Analyzing the values shown in Table 5, we can see lines that are overloaded to the limit of their capacity, that is, greater than $100 \%$. In the case of the power transfer of 1-2 a, just as $1-2 b$, the lines that are congested are 1-2 a and 1-2 b, both at $103.27 \%$. This means that there are two overloaded lines for both cases, which is the most critical scenario. However, in the other case of the power transfer of 2-3, only this line is overloaded, with $109.21 \%$ chargeability, meaning that lines with overloads are at risk of damage to their structure.

\subsection{Analysis of Results for the National Interconnected System}

The results obtained after the simulations were established in such a way that it was possible to calculate the DC Flow for the normal operation of the Ecuadorian system.

The values of active power flowing through the transmission lines of the network through the DC flow were obtained. In the system database, the maximum capacity in $M W$ of these lines was obtained to ascertain the respective loadings. In addition, the matrices of the sensitivity factors were found for the postcontingency analysis and, with this, it was determined if there would be a violation of limits.

\subsubsection{DC flow results for the National Interconnected System.}

The results of a part of the DC flow run are shown in Table VI, where the reactances of the lines that comprise the system are also available. There is a safe operation condition for the whole system, and the active power of each line making up the electrical network was obtained. Table 6 shows the lines that are the object of this study, given that they can exceed $100 \%$ of their chargeability. Line 11-16 has the origin node B_Cuenca_138 and ends at node B_Cuenca_69; it is a transmission line with a chargeability of $93.90 \%$, given the DC flow of $140.85 \mathrm{MW}$, and its maximum capacity in MW was 150.00 . For the case of line 37-200, corresponding to the union of bus B_Machala_230 with B_Frontera_Peru_230, there is no active power flowing through the line.

TABLE VI: Power Flow DC for the power system in a no fault state

\begin{tabular}{|c|c|c|c|c|}
\hline Line & X (p.u.) & $\begin{array}{c}\text { DC } \\
\text { Flow } \\
\text { (MW) }\end{array}$ & $\begin{array}{c}\text { Limit } \\
\text { MW }\end{array}$ & $\begin{array}{c}\text { \% } \\
\text { Charge }\end{array}$ \\
\hline $11-16$ & 0.06899727 & 140.85 & 150.00 & $93.90 \%$ \\
\hline $24-33$ & 004145683 & 77.40 & 80.07 & $96.66 \%$ \\
\hline $37-200$ & 0.05026 & 0.00 & 332.00 & $0.00 \%$ \\
\hline $39-1$ & 0.073398 & -175.22 & 375.00 & $46.73 \%$ \\
\hline $39-1$ & 0.073398 & -175.22 & 375.00 & $46.73 \%$ \\
\hline $42-59$ & 0.07809751 & 102.94 & 150.00 & $68.63 \%$ \\
\hline $46-49$ & 0.0648078 & 75.63 & 113.06 & $66.89 \%$ \\
\hline $46-49$ & 0.0648078 & 75.63 & 113.06 & $66.89 \%$ \\
\hline $46-91$ & 0.0431272 & 97.58 & 125.97 & $77.47 \%$ \\
\hline $46-91$ & 0.0431272 & 97.58 & 125.97 & $77.47 \%$ \\
\hline $63-46$ & 0.0715992 & 327.08 & 375.00 & $87.22 \%$ \\
\hline $63-46$ & 0,0730980 & 320,37 & 375,00 & $85,43 \%$ \\
\hline
\end{tabular}

Greater chargeability was present after carrying out the DC load flow in line 24-33 at $96.66 \%$, which corresponds to the start bus B_Monay (3)_69 and the final bus B_Turi(8)_69, as seen in Table 6. This is a distribution line, and so the output of this element was not taken into account in the contingency analysis.

3.2.2 Results of the loadings of the lines before contingency in the SNI through the LODF factors

The loading values in the lines were obtained with the LODF matrix of the Ecuadorian electrical network and the results of DC flows were obtained as in the previous section.

Table 7 shows the chargeability in each element before a single contingency event, consisting of the outputs of four transmission lines with start and end bus at a voltage level of $138 \mathrm{kV}$, and another by the exit of a distribution line with exit and arrival nodes at $69 \mathrm{kV}$. This line is taken into account given its effect on transmission, the other $69 \mathrm{KV}$ lines that belong to the distribution system are not considered, given that they do not present a significant contingency in the face of increased power flow. 
Under normal operating conditions there are no overloads, as discussed in the previous section. Then, in the postcontingency state, defined as the state that the system is in after a contingency, there are overloads, as shown in Table VII. When exceeding the maximum capacity, they are greater than $100 \%$. In the left column, the lines are being monitored before a contingency, on the right side are the contingencies present in the system, with the outputs of corresponding lines in order to analyse the effect at their service outage.

TABLE VII: Chargeability results with LODF for different outputs on the SNI lines.

\begin{tabular}{|c|c|}
\hline- & Outage \\
\hline Monitored & $\begin{array}{l}\text { B_PASCUALES_138- } \\
\text { B_CHONGON_138(1) }\end{array}$ \\
\hline $\begin{array}{c}\text { B_PASCUALES_138- } \\
\text { B_CHONGON_138(2) }\end{array}$ & $120.48 \%$ \\
\hline Monitored & $\begin{array}{l}\text { B_PASCUALES_138- } \\
\text { B_CHONGON_138(2) }\end{array}$ \\
\hline $\begin{array}{l}\text { B_PASCUALES_138- } \\
\text { B_CHONGON_138(1) }\end{array}$ & $120.48 \%$ \\
\hline Monitored & B_PASCUALES_138- \\
\hline $\begin{array}{l}\text { B_PASCUALES_138- } \\
\text { B_SALITRAL_138(2) }\end{array}$ & 132.99\% \\
\hline Monitored & B_PASCUALES_138- \\
& B_SALITRAL_138(2) \\
\hline $\begin{array}{l}\text { B_PASCUALES_138- } \\
\text { B_SALITRAL_138(1) }\end{array}$ & 132.99\% \\
\hline
\end{tabular}

At the first point before the output of line B_Pascuales_138B_Chongon_138 (1), where the flow is equal to zero, the parallel line corresponding to B_Pascuales_138 B_Chongon_138(2) is overloaded at $120.48 \%$ of its capacity. The same happens if the other line is out of service. On the other hand, before the service output of the element B_Pascuales_138-B_Salitral_138(1) there is an overload in line B_Pascuales_138-B_Salitral_138(2), with a value of $132.99 \%$. As in the previous case the output of line B_Pascuales_138-B_Salitral_138(2) also overloads the parallel line.

For the last case line B_Monay (3)_69-B_Turi(8)_69 is out of service, which causes the transmission line B_Cuenca_138B_Cuenca_69 to suffer an overload with a value of $109.10 \%$. With these events, there are overloads with a contingency in the lines of the system, for which these effects are considered by the operators of power systems to be able to mitigate their effect on the network.

The other part of the analysis of the overloads in the system before a contingency is shown in Table VIII. The left side corresponds to the transformer being monitored while the right shows the service outage of the respective transformer. For the calculation of the DC flow, the transformers are considered to be lines. The effect of the outage of the line B_Esmeraldas_138-B_Esmeraldas_69(1) is an overload of $146.49 \%$ in the parallel line. That is, given the outage of one of these elements, the other parallel one is overloaded, as in the following cases: if it is out of service B_Molino_230B_Molino_138(1) there is an overload in the other element of $111.45 \%$.

This is how you have different line outages and their effects on the network; the worst contingencies for the Ecuadorian electrical system are the outage of B_Pascuales_230-B_Pascuales_138(1) or B_Pascuales_230B_Pascuales_138(2), for the first case four elements are overloaded i.e. B_Pascuales_138-B_Salitral_138(1), B_Pascuales_138-B_Salitral_138(2), B_Pascuales_230B_Pascuales

_138(2), B_Trinitaria_230-B_Trinitaria_138 with $114.42 \%$, $114.42 \%, 145.89 \%, 124.00 \%$, respectively. The said element thus suffers severe damage in its useful life

TABLE VIII: Load results with LODF for different transformers outputs of SNI

\begin{tabular}{|c|c|}
\hline- & Outage \\
\hline Monitored & $\begin{array}{l}\text { B_PASCUALES_230 - } \\
\text { B_PASCUALES_138(1) }\end{array}$ \\
\hline $\begin{array}{l}\text { B_PASCUALES_138 - } \\
\text { B_SALITRAL_138(1) }\end{array}$ & $114.42 \%$ \\
\hline $\begin{array}{l}\text { B_PASCUALES_138 - } \\
\text { B_SALITRAL_138(2) }\end{array}$ & $114.42 \%$ \\
\hline $\begin{array}{l}\text { B_PASCUALES_230 - } \\
\text { B_PASCUALES_138(2) }\end{array}$ & $145.89 \%$ \\
\hline $\begin{array}{l}\text { B_TRINITARIA_230 - } \\
\text { B_TRINITARIA_138 }\end{array}$ & $124.00 \%$ \\
\hline Monitored & $\begin{array}{l}\text { B_PASCUALES_230 - } \\
\text { B_PASCUALES_138(2) }\end{array}$ \\
\hline $\begin{array}{l}\text { B_PASCUALES_138 - } \\
\text { B_SALITRAL_138(1) }\end{array}$ & $113,12 \%$ \\
\hline $\begin{array}{l}\text { B_PASCUALES_138 - } \\
\text { B_SALITRAL_138(2) }\end{array}$ & $113.12 \%$ \\
\hline $\begin{array}{l}\text { B_PASCUALES_230 - } \\
\text { B_PASCUALES_138(1) }\end{array}$ & $146.81 \%$ \\
\hline $\begin{array}{l}\text { B_TRINITARIA_230 - } \\
\text { B_TRINITARIA_138 }\end{array}$ & $122 / 45 \%$ \\
\hline
\end{tabular}

Table 8 shows the corresponding loading lines being monitored before an output from another line.

When carrying out the contingency analysis using LODF factors, the worst scenario is obtained before the transformer output B_Pascuales_230-B_Pacuales_138(1) or B_Pascuales_230-B_Pacuales_138(2). There are four contingencies that respond to the monitored lines, and the effect on their chargeability can cause imperfections in its operation.

In summary, the calculation of the sensitivity factors in a test system was carried out, in order to perform a contingency analysis to know the safety of the network, the state of the electrical network was previously known, and thus by means of an evaluation of the loadings of the elements of transmission information can be provided about the post-contingency status. Depending on the damage that exists, decisions can be carried out to improve the continuity of the electrical system. 
3.2.3 Results of the loadings of the lines before a contingency in the SNI through the PTDF factors

To carry out the simulation of the loadings of transmission lines, the bus that delivers active power is selected and the point of reception of the energy is determined. The interconnection between Ecuador and Colombia is given by the Pomasqui and Jamondino bus, respectively, at a voltage level of $230 \mathrm{kV}$. For the interconnection between Ecuador and Perú, this is through the line that joins the Machala bus with the Zorritos bus in the neighbouring country.

Table IX shows the loadings in the lines of the Ecuadorian network which give a transfer between two buses: one belongs to the system in Ecuador that was sending energy corresponding to the Mill bus at a voltage level of $138 \mathrm{kV}$, while the power reception bus belongs to the Frontera Perú or Zorritos $230 \mathrm{kV}$ bus.

TABLE IX: Loadings of lines of SNI for a power transfer between Ecuador and Perú. From Molino Bus $138 \mathrm{kV}$ to the frontier Bus, Perú $230 \mathrm{kV}$

\begin{tabular}{|l|c|}
\hline \multicolumn{2}{|c|}{ Power transfer of 30 MW } \\
\hline Monitored Line & \%Chargeability \\
\hline B_Cuenca_138-B_Cuenca_69 & $95.41 \%$ \\
\hline \multicolumn{2}{|c|}{ Power transfer of 60 MW } \\
\hline Monitored Line & \%Chargeability \\
\hline B_Cuenca_138-B_Cuenca_69 & $96.92 \%$ \\
\hline \multicolumn{2}{|c|}{ Power transfer of 100 MW } \\
\hline Monitored Line & \%Chargeability \\
\hline B_Cuenca_138-B_Cuenca_69 & $98.92 \%$ \\
\hline
\end{tabular}

When transferring power equal to 30,60 or $100 \mathrm{MW}$, there were no overloads in the other lines in the system, however, it was possible to see a transmission line that could exceed its capacity limit. This monitored line was B_Cuenca_138B_Cuenca_69, with greater than $90 \%$ chargeability, where there is a risk that its operation could be affected over time. In the first case with $30 \mathrm{MW}$, the monitored line corresponded to a value of $95.41 \%$. When the energy transfer increased, it can be noted from Table 9 that the line belongs to the Cuenca bus, the load that flows through it increases until it reaches $100 \mathrm{MW}$, which in the end is $98.92 \%$ and thus close to $100 \%$ of its capacity. Under the values of the analysed transfer, the lines fail to saturate, and continue to work in normal operation.

The other case that was analysed was the import of energy from Perú through the Zorritos bus, with the power transfers considered in the export seen previously. See X.

Table 10 considers a power transfer event for the Zorritos to Molino bus, in the case of energy import to Ecuador, where there are no lines working almost at full capacity, and increased energy transfer of 30,60,100 MW. The line corresponding to B_Cuenca_138-B_Cuenca_69 has a chargeability of $92.41 \%, 90.90 \%, 88.90 \%$, respectively, as this line's chargeability decreases without affecting the transmission lines.

In the case of the exchange of active power from 30 to 60 MW between the countries of Ecuador and Perú, there were
TABLE X: Loadings of the SNI lines for power transfer between Perú and Ecuador. From Zorritos Bus $230 \mathrm{KV}$ to Molino Bus $138 \mathrm{KV}$

\begin{tabular}{|l|c|}
\hline \multicolumn{2}{|c|}{ Power transfer of 30 MW } \\
\hline Monitored Line & \%Chargeability \\
\hline B_Cuenca_138-B_Cuenca_69 & 92,41\% \\
\hline \multicolumn{2}{|c|}{ Power transfer of 60 MW } \\
\hline Monitored Line & \%Chargeability \\
\hline B_Cuenca_138-B_Cuenca_69 & 90.90\% \\
\hline \multicolumn{2}{|c|}{ Power transfer of 100 MW } \\
\hline Monitored Line & \%Chargeability \\
\hline B_Cuenca_138-B_Cuenca_69 & 88.90\% \\
\hline
\end{tabular}

no overloads in the monitored lines, so that the lines did not saturate, and continued working in normal operation.

Table XI shows the loadings that the lines present in the Ecuadorian electrical system in the face of an energy transfer from the mill bus for cases of export of power to Colombia through the Jamondino bus. Line B_Cuenca_138B_Cuenca_69 is monitored and suffers an effect on its chargeability depending on the power transfer, being $104.27 \%$ higher than its maximum capacity from $200 \mathrm{MW}$, until from $500 \mathrm{MW}$ it reaches $119.81 \%$ of chargeability. The lines of B_Molino_138-B_Molino_230 are affected in parallel to a chargeability of $108.21 \%$, with which the worst scenario occurs at $500 \mathrm{MW}$ and three lines of the network are affected. This report is indicative of the problems of the loading of the transmission lines for the monitoring of the security of the Ecuadorian network before export to Colombia.

TABLE XI: Loadings of lines of SNI given a power transfer between Ecuador and Colombia.

\begin{tabular}{|l|c|}
\hline \multicolumn{2}{|c|}{ Power transfer of 200 MW } \\
\hline Monitored Line & \%Chargeability \\
\hline B_Cuenca_138-B_Cuenca_69 & $104.27 \%$ \\
\hline \multicolumn{2}{|c|}{ Power transfer of 300 MW } \\
\hline Monitored Line & \%Chargeability \\
\hline B_Cuenca_138-B_Cuenca_69 & 109.45\% \\
\hline \multicolumn{2}{|c|}{ Power transfer of 400 MW } \\
\hline Monitored Line & \%Chargeability \\
\hline B_Cuenca_138-B_Cuenca_69 & 114.63\% \\
\hline \multicolumn{2}{|c|}{ Power transfer of 500 MW } \\
\hline Monitored Line & \%Chargeability \\
\hline B_Cuenca_138-B_Cuenca_69 & $119.81 \%$ \\
\hline B_Molino_138-B_Molino_230 & $108.21 \%$ \\
\hline B_Molino_138-B_Molino_230 & $108.21 \%$ \\
\hline
\end{tabular}

In the last case, an import of energy from the $230 \mathrm{kV}$ Jamondino bus in Colombia to the Molino bus located in Ecuador was considered. See Table XII.

Table 12 shows a monitored line corresponding to B_Cuenca_138-B_Cuenca_69, as the one with the highest percentage of chargeability, without overloading. In the case 
TABLE XII: Loadings of the SNI lines for a power transfer between Colombia and Ecuador.

\begin{tabular}{|l|c|}
\hline \multicolumn{2}{|c|}{ Power transfer of 100 MW } \\
\hline Monitored Line & \%Chargeability \\
\hline B_Cuenca_138-B_Cuenca_69 & 92.51\% \\
\hline \multicolumn{2}{|c|}{ Power transfer of 200 MW } \\
\hline Monitored Line & \%Chargeability \\
\hline B_Cuenca_138-B_Cuenca_69 & 88.27\% \\
\hline \multicolumn{2}{|c|}{ Power transfer of 300 MW } \\
\hline Monitored Line & \%Chargeability \\
\hline B_Cuenca_138-B_Cuenca_69 & 88.27\% \\
\hline \multicolumn{2}{|c|}{ Power transfer of 400 MW } \\
\hline Monitored Line & \%Chargeability \\
\hline B_Cuenca_138-B_Cuenca_69 & 79.77\% \\
\hline
\end{tabular}

of a $100 \mathrm{MW}$ power transfer, the load capacity of this line reached $92.51 \%$ from Colombia. If the power transfer is increased to $200 \mathrm{MW}$, the chargeability of the monitored line drops to $88.27 \%$ of its maximum capacity. With a power transfer of $300 \mathrm{MW}$ the line did not undergo changes in its chargeability, and with $400 \mathrm{MW}$ the system was still in operation without any overload. The chargeability in the line from the bus Jamondino $230 \mathrm{kV}$ up to the bus Mill $138 \mathrm{kV}$ decreases up to $79.77 \%$, that is, it does not suffer damage to the lines with the given import.

After obtaining the PTDF matrix and assigning an energy transfer between Ecuador-Colombia and Ecuador-Perú, the worst event that occurred was an export of energy to Colombia. When making power transfers from 100 to $500 \mathrm{MW}$, it was seen that $500 \mathrm{MW}$ overloaded three lines corresponding to B_Cuenca_138-B_Cuenca_69 with $119.81 \%$ chargeability, the lines of B_Molino_138-B_Molino_230 were also affected in parallel to a chargeability of $108.21 \%$. Given the topological change that has occurred in the Ecuadorian electrical system, these studies showing the effect of certain contingencies on the operation of the network must now be analysed.

\section{DISCUSSION AND CONCLUDING REMARKS}

In this section, we discuss the results obtained in the simulations given by the input values of the National Interconnected System, how the analysis of electrical parameters of the elements was implemented, and the topology of the network, including the number of each bus and lines, as this was the way the configuration of the system simulation was obtained. The parameters used for the buses of the power system were generation and maximum demand during the dry period, as seen in the Methodology section. The type of bus and the lines of the network are identified as the union of two buses, taking into account the start and end of the pair of buses for the simulation, given that the DC flow, whose definition and importance is raised in Section Two, can be positive or negative, as shown in the Results section.

In this article, the flow diagram seen in Section 2 was proposed to enable the calculation of the sensitivity factors and the line reactance that was used as an electrical parameter and the fourteen buses of the IEEE were simulated for validation in the context of the Ecuadorian electrical system. In this work, the main variable is the one that corresponds to active power, that is, how it changes, and the effect it has after an output of an element. In our case, these are network transmission lines, or a change of power transfer between bus, how the active powers of the lines that belong to the system react, since, depending on the interruption, it will affect some with respect to others.

In our research, a restructuring of the original Ecuadorian electric transport system was made with some considerations in which the equivalent simulation is allowed for a reduced system to facilitate the analysis of the network.

For this, a reductive method was carried out that allows changes in topology of the system based on the elimination of buses that are not relevant in the original structure. With respect to the parameters corresponding to the elements of the network, these remain the same, but the limitations in the simulations must be taken into consideration when eliminating nodes to obtain the DC flow. Having said this, we do not depart from the actual configuration that describes the original system.

For the creation of the electrical scheme of the Ecuadorian electrical system, the following considerations were made: actual values of the lines and TRANSELECTRIC substations, were provided for a period of drought, and the power generated and consumed is 4,115.5 MW in 2018. In total, the system has 200 buses consisting of: 63 buses of $69 \mathrm{kV}, 91$ buses of 138 $\mathrm{kV}, 41$ buses of $230 \mathrm{kV}$ and five buses with a voltage level of $500 \mathrm{kV}$.

The total number of lines in the network is 242 elements and 74 transformers, which are considered a component of the system since for the DC flow the transformers are considered lines. A total of 316 lines connect the different nodes of the network. For the buses of the electrical network carrying out the flow of the DC load, these were assigned as follows. The reference node was assigned to the B_Molino_138 bus, which belongs to the Paute Integral Hydroelectric Complex. The considerations that correspond to this node for the simulation are: it is established as one with respect to bus number, the power generated in the node, and, the power consumed, respectively.

The transmission lines were represented by assigning the initial bus number as the final node, which is important because the line length was not taken into account, and the values were taken as per unit of the reactance, neglecting the data of resistance. In addition, the maximum capacity of the lines was found, allowing for the maximum flow without there being violations due to overload.

With respect to the transformers of the two windings that exist in the electrical network, these were considered as lines for the simulation, having the data of reactance and connections of transformers between buses. For the transformers of the three existing windings in the system, the input data were known as initial bus number, and two numbers of nodes corresponding to the output of voltages. For this case, when working in DC flow, it is necessary to convert these transformers into an equivalent line that connects to the respective bus of the system.

With the original model we worked with DigSILENT ${ }^{T M}$ to make the comparison with the topology of the network 
where buses in the network were eliminated. Given that the Ecuadorian electrical system has more than 600 buses, it is complicated to carry out a simulation given the extensiveness of the corresponding data in order to carry out the resolution of the state in normal operation, that is, the state in which the power system operates is defined. In Section 3, we saw that the contingency analysis using sensitivity factors requires DC flow for a simulation of the operation of the real system, so to carry out all the programming, it was necessary to implement functions in Matpower. To solve the DC flow in a system, we used AC flow equations.

For the resolution of the continuous load flow for any network, a reference bus that is decided according to individual needs is taken into consideration. There are input parameters for the bus, its type, and indices for generation and loads, in the same way there are also input parameters for the reactance of the lines (X). To calculate the powers in the lines, we used matrix B susceptance and the matrix of the differences of angles. The flow of DC power was calculated to ascertain the power flows in the transmission lines and transformers, to indicate the direction of power flows in each transmission line of the network.

The Matpower tool was selected to perform the simulations because it is a tool which provides manuals to facilitate it adaptation to programs such as Excel, to which a database used for Matlab simulations was exported. This permitted the use of calculations in the form of matrices and vectors in fast programs, which was suited to the number of variables and functions. We also used techniques for the handling of the information to save computer memory, which is evidenced in the effectiveness of the results obtained in Section 3.

The PTDF factor proceeds to a quick calculation without having to use many iterations. Because the calculation is linear, you can superposition the factors when transfers are required between any pair of buses not directly connected. This was performed in this work to create the complete matrix of PTDF, from any node to another node, by combining the PTDFs that exist in a the direct connection between buses, that is to say the sum of the corresponding factors in order to take the shortest path.

The LODF factor is based on the calculation of a line's output, when the interruption of this element entails the redistribution of the remaining lines of the network, which are called monitored lines. The analysis is very important given that in a power system this type of contingency can occur, and the impact of of a outage in the line must be determined.

The sensitivity factors can be calculated in at least two different ways. The algorithm chosen in this research was the simplest one, that is, through the use of the DC flow seen in Section 2. In this way the factors provide an approximation of the state of the elements of the system before a change in the power transfer in the network, or before the outage of a component, as shown in Section 3, given the assumptions that this model involves, as seen in Section 2.

The obtained results indicated the state in normal operation, being the case of pre-contingency, where the loadings of the lines of the network are as presented in Section 3. For the postcontingency state, which is a report on the major contingencies obtained after running the program, these tables summarize the security and contingency analyses by simulating the sensitivity factors.

Once the contingency reports have been obtained, the network diagnosis is carried out, with real values for the operator to subsequently select the best alternative to maintain the system within its limits in the loadings of the lines.

The DigSILENT tool also permits consideration of the mitigation of overload which occurs in the SNI, or in any other electrical network following a re-dispatch procedure in lines. This allows the control of the dispatch that the generators have, according to their capacity, being careful not to exceed the maximum generation limits of each unit, to avoid further inconvenience within the system, since cascading events can occur even with a simple contingency.

The analysis was carried out taking into account the voltages levels of the transmission system in the Ecuadorian electrical system, and does not consider the electricity distribution lines seen in the original system, which is complete. A reduced system with a DC load flow was implemented, and in turn the factors that depend on the initial flows in direct current for the post-contingency analysis were assessed.

When carrying out a safety evaluation of an electrical network, it is possible to detect violations in the limits of electrical parameters, given the operating status of the network, which in our case were the loadings of the transmission lines of the test system and the National Interconnected System. In addition, variables that may cause some overload are monitored so that an eventuality is determined early. The contingency analysis allows the operator of power electrical systems to make decisions based on the effects that certain faults in the network would have on modifying physical variables, such as line output and power increase.

To carry out a contingency analysis, it is recommended to make use of factors, such as Outage Transfer Distribution Factor OTDF, because of the power resulting in one element after two contingency events in another element. This must also take into consideration an injection of power in a bus, and, in this study, this is done by means of system restrictions in case of overloads due to a simple contingency. This factor is related to network parameters that directly influence the transfer of active power, the importance of this factor is that it indicates the effect of a contingency on each system component.

For the test of the Ecuadorian electrical system, the calculation of the DC Load Flow was performed, with MatPower, because it is a non-complex non-iterative method. The results obtained are given in Section 3, and provided the input data for the power flows in the lines to determine their loadings in the system through sensitivity factors, as shown in the same section.

The purpose of this research was to carry out a contingency analysis using sensitivity factors for the improvement of the SNI. In a first stage, a check was made using a small IEEE system of fourteen buses. After the simulations, the matrices of the PTDF, LODF factors were generated to obtain new flows in the transmission lines of the system, using required information on the behaviour of the lines in a stable state 
through a flow of DC power. It could then be seen whether there were overloads in the electricity grid after a contingency.

The usefulness of this type of study is to publicize the limitations and risk zones when designing, protecting or operating power systems, based on sensitivity factors, and to act in a planned and appropriate manner when unforeseen events occur. The application of a contingency analysis, in this case by means of sensitivity factors, offers the operator a better understanding an improvement in the performance of their power systems, for which safety studies are carried out in the SNI by the operators of the system. It makes decisions which keep the state in normal operation.

It is important to conduct the type of contingency and safety analysis studies seen in this paper because they seek to resolve the contingencies in the shortest possible time. In this case, we can observe that the values obtained do not exceed the limits of the elements of the system, and that the operator has the necessary information to be able to fulfil the corrective tasks.

The present article was executed to study the contingency events in the SNI through the use of sensitivity factors, and a programming was implemented in Matlab to execute the simulations of the factors in matrix form. The use of these tools allows the evaluation of security. After the security assessment identifies the contingencies by which the system can reach an unwanted state, it proceeds to determine actions to control the system and maintain a safe state with no inconvenience. These actions can be both preventive and corrective.

As a final remark, the tools and analysis of this paper might be applied internationally.

\section{ACKNOWLEDGMENTS}

This article would not have been possible without the help received by the National Transmission Company TRANSELECTRIC, who allowed us to use their data set.

\section{REFERENCES}

[1] L. Kristov, "The bottom-up (R)evolution of the electric power system: The pathway to the integrated-decentralized system," IEEE Power and Energy Magazine, vol. 17, no. 2, pp. 47-49, 2019. [Online]. Available: https://doi:10.1109/MPE.2018.2885204

[2] MEER, "Plan Maestro de Electrificación 2013-2022 [2013-2022 Electricity National Plan]," MEER, Tech. Rep., 2013. [Online]. Available: https://www.regulacionelectrica.gob.ec/planmaestro-deelectrificacion-2013-2022/

[3] North American Electric Reliability Corporation, "Balancing and frequency control: A technical document prepared by the NERC resources subcommiittee," NERC, Princeton, New Jersey, Tech. Rep., Jan. 2011. [Online]. Available: https://www.nerc.com/docs/oc/rs/ NERCBalancingandFrequencyControl040520111.pdf

[4] E. Apupalo, "Evaluación e implementación de esquemas de protección sistémicas ante contingencias críticas en el sistema nacional interconectado [Evaluation and implementation of systemic protection schemes against critical contingencies in the national interconnected system]," Escuela Politécnica Nacional, Tech. Rep., 2018. [Online]. Available: http://bibdigital.epn.edu.ec/handle/15000/19637

[5] S. A. Blumsack, P. Hines, M. Patel, C. Barrows, and E. C. Sanchez, "Defining power network zones from measures of electrical distance," in 2009 IEEE Power and Energy Society General Meeting, PES '09 [5275353], 2009. [Online]. Available: https: //doi.org/10.1109/PES.2009.5275353

[6] P. Li, J. Liu, B. Li, Y. Song, and J. Zhong, "Dynamic power system zone division scheme using sensitivity analysis," Journal of International Council on Electrical Engineering, vol. 4, no. 2, pp. 157-161, 2014. [Online]. Available: https://doi:10.5370/JICEE.2014.4.2.157
[7] MEER, "Plan Maestro de Electrificación 2016 - 2025 [2016 - 2025 Electricity Master Plan]," MEER, Tech. Rep., 2017. [Online]. Available: https://www.celec.gob.ec/hidroagoyan/index.php/ plan-maestro-de-electricidad-2016-2025

[8] R. Billinton and R. Allan, "Basic power system reliability concepts," Reliability Engineering \& System Safety, vol. 27, no. 3, pp. 365-384, 1990. [Online]. Available: https://doi.org/10.1016/0951-8320(90)90007A

[9] J. Villacís and F. Chalá, "Análisis técnico en estado estable de contingencias en el Sistema Nacional Interconectado [Steady state technical analysis of contingencies in the National Interconnected System,” Escuela Politécnica Nacional, Tech. Rep., 2007. [Online]. Available: http://bibdigital.epn.edu.ec/handle/15000/156

[10] V. J. Mishra and M. D. Khardenvis, "Contingency analysis of power system," in IEEE Students' Conference on Electrical, Electronics and Computer Science, Bhopal, 2012, pp. 1-4.

[11] A. Fradi, S. Brignone, and B. E. Wollenberg, "Calculation of energy transaction allocation factors," IEEE Transactions on Power Systems, vol. 16, no. 2, pp. 266-272, May 2001. [Online]. Available: http://ieeexplore.ieee.org/stamp/stamp.jsp?tp $=\backslash \&$ arnumber $=$ $918297 \backslash \backslash \backslash$ \&isnumber $=19855$

[12] C. S. Song, C. H. Park, M. Yoon, and G. Jang, "Implementation of ptdfs and lodfs for power system security," Journal of International Council on Electrical Engineering, vol. 1, no. 1, pp. 49-53, 2011.

[13] M. Majidi-Qadikolai and R. Baldick, "Integration of n-1 contingency analysis with systematic transmission capacity expansion planning: Ercot case study," IEEE Transactions on Power Systems, vol. 31, no. 3, pp. 2234-2245, 2016. [Online]. Available: https://ieeexplore.ieee.org/ abstract/document/7130682

[14] D. Van Hertem, J. Verboomen, K. Purchala, R. Belmans, and W. L. Kling, "Usefulness of dc power flow for active power flow analysis with flow controlling devices," in 8th IEE International Conference on AC and DC Power Transmission, London, UK, 2006, pp. 5862. [Online]. Available: http://ieeexplore.ieee.org/stamp/stamp.jsp?tp= $\backslash$ \&arnumber $=1633613 \backslash \backslash \backslash$ \&isnumber $=34251$

[15] J. Guo, Y. Fu, Z. Li, and M. Shahidehpour, "Direct calculation of line outage distribution factors," IEEE Transactions on Power Systems, vol. 24, no. 3, pp. 1633-1634, 2009. [Online]. Available: https://ieeexplore.ieee.org/document/5130240

[16] A. J. Wood and B. F. Wollenberg, Power Generation, Operation, and Control. Wiley-Interscience, 1984. [Online]. Available: http://www.amazon.com/exec/obidos/redirect?tag=citeulike07-20 \&path=ASIN/0471586994

[17] Y. C. Chen, A. D. Domínguez-García, and P. W. Sauer, "Online computation of power system linear sensitivity distribution factors," in IREP Symposium Bulk Power System Dynamics and Control IX Optimization, Security and Control of the Emerging Power Grid, 2013, pp. 1-4. [Online]. Available: https://ieeexplore.ieee.org/document/ 6629394

[18] D. Sosic, I. Skokljev, and N. Pokimica, "Features of power transfer distribution coefficients in power system networks." INFOTEHJAHORINA, 2014. [Online]. Available: https://infoteh.rs.ba/zbornik/ 2014/radovi/ENS-1/ENS-1-6.pdf

[19] M. Liu and G. Gross, "Role of distribution factors in congestion revenue rights applications," IEEE Transactions on Power Systems, 2004. [Online]. Available: https://ieeexplore.ieee.org/document/1294985 